\title{
Technology Embedding of Classroom Teaching: Types, Issues and Responses
}

\author{
Xiaojun Wei \\ School of Teacher Education, Sichuan University of Arts and Science, Dazhou, China \\ Email:scdzwxj@163.com
}

How to cite this paper: Wei, X.J. (2020) Technology Embedding of Classroom Teaching: Types, Issues and Responses. Open Journal of Applied Sciences, 10, 409-415. https://doi.org/10.4236/ojapps.2020.106028

Received: May 19, 2020

Accepted: June 27, 2020

Published: June 30, 2020

Copyright ( 2020 by author(s) and Scientific Research Publishing Inc. This work is licensed under the Creative Commons Attribution International License (CC BY 4.0).

http://creativecommons.org/licenses/by/4.0/

\begin{abstract}
As the new demands on curriculum teaching in the information age, the application of various technologies is profoundly affecting classroom teaching today. The technology-embedded classroom approach includes technologyassisted teaching, technology-integrated teaching, and technology-based teaching. There are still some deficiencies in the technological embedding of course teaching, the technological presentation of knowledge destroys the ecosystem of classroom, the technological controlled teaching hinders the development of teacher-student relationship, and the value orientation under technological efficiency neglects the integrated development of students. It is recommended to develop an ecological view of technological development, a pedagogical system focused on teacher-student interaction and an evaluation system with a multi-valued orientation.
\end{abstract}

\section{Keywords}

Types, Issues, Responses, Top-Level Design, Problem Solving, Pluralistic Value

\section{Types of Technology-Embedded Teaching}

Classroom teaching in the information age emphasizes students as the subject, the learning process as the carrier and the cultivation of students' abilities as the focus, and is a bilateral teaching activity in which teachers and students make full use of various teaching resources. However, when technology entered the classroom, it reconstructed the original classroom teaching system due to the self-organizing nature of technology. In recent years, due to teachers' different perceptions of technology-embedded teaching, various types of course teaching under technical support have formed; the teaching of technology-embedded classroom includes technology-assisted teaching, technology-integrated teaching and 
technology-based teaching [1].

\subsection{Technology-Assisted Course Teaching}

Technology-assisted course teaching means that technology as a way of teaching can only be subordinated to the role of the teacher and the student, and plays a supplementary role to classroom teaching. The first is teacher-centered technology-assisted teaching, which holds that classroom instruction is still teacher-centered, with students, content, instructional technology, etc. as objects. This view of teachers as meeting the various needs of students through a variety of technologies does not value the subjectivity of students, only the way in which the teaching content is presented has changed. The second is the student-centered technology-assisted teaching. It believes that the classroom is student-centered, and that teaching activities can only be meaningful if students can mobilize their own motivation and initiative through the information-based teaching platform and it relies on the active construction of students [2]. However, it does not attach importance to the role of teachers in the classroom, resulting in the weakening of teachers' role in the informationalized teaching.

\subsection{Technology-Integrated Teaching}

Technology-integrated teaching means that in classroom teaching, teacher, student and technology interact and influence each other, and are on equal footing. First is the leading-subject technology-integrated teaching. It holds that in the classroom teaching process, the teacher is in a leading position, and the teacher exerts influence on students, i.e. the subject, through various technological means; the leading-subject technology-integrated teaching should not only reflect the teacher's teaching leadership in informatization, but also develop students' independent learning ability in informatization, while emphasizing the integration of various technologies and courses. The second is the interactive-subject technology-integrated teaching [3]. It holds that the subject of the classroom should not be chosen between teacher and students, because either way will weaken the one side's position. The classroom teaching process should be one in which teacher and students interact together as equal subjects, using various technologies.

\subsection{Technology-Based Classroom Teaching}

Technology-based course teaching means that teacher and students learn communicatively in the presence of technology, which provides the environment and resources for classroom instruction. Technology-based classroom teaching is manifested in a model that is centered on the information-based teaching environment and resources. It holds that classroom teaching is carried out in a certain teaching environment and resources; first of all, it is necessary to create a new teaching environment that can meet the needs of many teaching functions; in this environment, students are encouraged to show enthusiasm and conscien- 
tiousness in learning, so as to realize the transformation from "I am asked to learn" to "I want to learn" and the fundamental changes in education and teaching [4]. Secondly, in order to ensure the full play of students' initiative, teachers should play the role of guide, helper and supervisor in the teaching process.

\section{Problems in the Technology-Embedded Teaching}

Knowledge-based view, teacher-student relationship, and students' perspective are the three elements of the classroom teaching, as well as a fundamental factor of technology-embedded classroom teaching. From the experience of a large number of classroom practices, there are still some deficiencies in the technology-embedded teaching. Technological presentation of knowledge destroys the ecosystem of classroom, technology-controlled teaching and learning process hinders the development of teacher-student relationship, and the value orientation under technological efficiency neglects the integrated development of students.

\subsection{The Technological Presentation of Knowledge Destroys the Ecosystem of Classroom}

Classroom Teaching in the Modern Information Technology EnvironmentFirst, technology has brought about the digitization of subject knowledge, and teachers use a range of technologies to build the system of knowledge for their students. But such a system can hardly resonate with students, whose knowledge and skills are supposed to derive from their learning practices. Technological knowledge is doomed to lose its vitality. Secondly, because of the technicalization of knowledge dissemination, students are immersed in the informationalized teaching environment created by technologies, which replaced the original sense of problem and context in the classroom, making the original teacher-student communication into technology dissemination, resulting in the destruction of the ecosystem of courses [5].

\subsection{The Technology-Controlled Teaching Hinders the Development of Teacher-Student Relationship}

Under the influence of various technologies, the modern teaching turns classroom teaching into a process of knowledge transfer and skill migration characterized by technological control, which ignores the interaction between teachers and students [6]. The process of classroom teaching with technical support creates a technological barrier between teachers and students and constrains the teacher's original teaching style, resulting in a loss of motivation for teacherstudent interaction in the process.

\subsection{Value Orientation under Technological Efficiency Neglects the Integrated Development of Students}

The classroom teaching under technological efficiency neglects the value pursuit aimed at the development of students' personalities. For students, technology 
can impart more knowledge and skills in a shorter period of time, bringing them closer to what they can achieve. However, classroom teaching in the pursuit of "technological efficiency" places too much emphasis on improving teaching performance through technology and neglects the development of students' personalities; technological teaching scenarios lost the diversity of students' personalities, and would ultimately ignore the subjective values of students [7].

\section{Realistic Responses to Technology-Embedded Teaching}

\subsection{Top-Level Design as a Guiding Principle: Establish an Ecological Perspective on Technological Development}

The embedding and development of classroom teaching technologies depends on the development of teachers' teaching skills in informatization. The development of teachers' teaching ability in informatization is a systematic and continuous process. For a long time, however, researchers have been looking at the impact of technology on education largely from a utilitarian perspective, with results that often fall short of expectations. For example, some researchers believe that the use of new media and technologies is aimed at improving the efficiency of teaching and learning, thus making the modern teaching and learning a process of technological control. There are also researchers who focus on students' using of online education and virtual experimental platforms to complete their own learning, neglecting of the teachers' role [8]. The importance of schools in the informationalized education is the top-level design, which guides the development concept and direction of teachers' teaching ability in informatization. Schools should pay attention to the living environment of teachers and improve their teaching ability in informatization; besides being influenced by teachers' own ability and information literacy, they should consider the subject they teach and the educational needs of students and society. Therefore, in order to develop teachers' teaching ability in informatization in this context, it is necessary to establish an ecological view of technological development, which is mainly manifested by giving teachers the autonomy to apply various skills, facing teachers and students with an aesthetic attitude, fully mobilizing the subjective initiative of teachers, letting teachers identify with technology and practice it creatively, thereby contributing to the improvement of their teaching skills in informatization.

\subsection{Problem-Solving Orientation: Teaching System that Focuses on Teacher-Student Interaction}

The technology-embedded course teaching should be an interactive process in which teachers and students interact with technology with problem-solving orientation. Under the role of various technologies, the traditional teacher-student relationship in the modern teaching has changed from a human-to-human relationship to a "human-technology-human" one; human's dependence on technology even exceeds the human-to-human relationship, resulting in strong utili- 
tarianism in teaching and the destruction of the original teaching ecology. The teacher-student relationship, led by information technology, has become a "functional relationship". The lack of sincere communication between teachers and students under the technology-controlled process hinders the realization of the values of the teaching subject. Therefore, the technological embedding of classroom instruction should focus on building the ecosystem of classroom for teacher-student interaction. The classroom process should be a spiritual interaction and dialogue between teachers and students based on new media and technologies. Only by giving teachers a role in the dissemination of knowledge and letting them engage in an honest dialogue with their students with their knowledge and full experience can the mutual growth of teachers and students be promoted. In the meanwhile, the application of technological means by teachers should become a phenomenon of self-awareness. Teachers should continuously integrate practice, conduct self-reflection, make full use of various technical means to serve teaching, focus on problem-oriented design as an entry point, mobilize students' motivation, and make the best of different technical means to solve various problems in teaching [9].

\subsection{Aim at the Development of Students Build an Evaluation System with a Multi-Valued Orientation}

The ultimate goal of technology embedding in classroom instruction should be implemented for the integrated development of students, as manifested in their knowledge learning and skills migration. However, technology-embedded course evaluation, influenced by utilitarianism, has not been freed from the single-valued orientation that focuses too much on outcomes assessment, the results of which will inevitably hinder the integrated development of students. The value orientation of technology embedding in the classroom should be the mutual growth and self-development of both teachers and student, while also meeting the personalized needs of students. Specifically, first of all, the technology-embedded course evaluation should meet the basic demands of society, schools, teachers, students and other subjects with pluralistic values, not highlighting one aspect at the expense of others, and allowing evaluation criteria to adjust dynamically. Secondly, the technology-embedded course evaluation should focus on the developmental of students, not only for the individual differences of students and the evaluation criteria adapted to their genders, personalities and abilities for their growth, but also through the use of various technological means to meet their increasing diversified needs of learning, so as to achieve the comprehensive development of each one [10]. Therefore, the technology-embedded course evaluation should construct an evaluation system with multi-valued orientation to meet the needs of teachers and students' value development, thus promoting the integrated growth of students.

\section{Conclusion}

Classroom is a vital place to lead students into professional fields. The research 
on the technological embedding of course teaching is the research on the technological in the classroom, rather than being separated from the existing environment. Instead of staying at the stage of using media tools and discussing how to apply new technology to teaching environment [11]. The technology-embedded course teaching should be an interactive process in which teachers and students interact with technology with problem-solving orientation. Therefore, it is recommended to develop an ecological view of technological development, a pedagogical system focused on teacher-student interaction and an evaluation system with a multi-valued orientation, meanwhile teachers should study subject content in depth, actively use various technical means, and integrate it with subject content, so as to truly adapt to the new requirements of the times for teachers, thus making technology in classroom teaching full of vitality.

\section{Fund Projects}

A Project Supported by Scientific Research Fund of Sichuan Provincial Education Department (18SB0621).

\section{Conflicts of Interest}

The author declares no conflicts of interest regarding the publication of this paper.

\section{References}

[1] Zhu, D.Q. and Peng, L. (2018) Technological Rationality and Its Transcendence in College Teaching. Educational Research, 8, 76.

[2] Wei, X.J. (2019) The Dilemma and Transcendence of Information Technology Applications in Language Teaching. Language Planning, 14, 65.

[3] Shi, Z.Y. (2007) Educational Philosophy. Beijing Normal University Publishing Group, Beijing, 160 .

[4] Miao, Y. (2019) Technical Embedding in Vocational Education: Principles, Alienation and Correction. Vocational \& Technical Education Forum, 8, 153.

[5] Xu, J.C. and Che, L.N. (2015) Technical Embedding in Teaching and Its Stipulations. Curriculum, Teaching Material and Method, 35, 12-17.

[6] Liu, Z. and Yin, R. (2014) The Connotation and Improvement of Teachers' Teaching Ability in Informatization. Journal of the Chinese Society of Education, 10, 31-36.

[7] Liu, B. (2013) Theoretical Reflections on the Effectiveness of Informationalized Teaching-A Re-Awareness of the Nature of Informationalized Teaching. Modern Educational Technology, 23, 26-30.

[8] Wang, W.J. (2012) A Study on the Development Strategies for Teachers' Teaching Ability in Informatization. E-Education Research, 33, 103-109.

[9] Li, T.L. (2011) Deep Analysis on the Developmental Pathways of Young College Teachers' Teaching Ability in Informatization. E-Education Research, 12, 106-109+ 120.

[10] Zhao, J. and Guo, S.Q. (2010) A Research Review on Teaching Ability in Informatization. Modern Distance Education, 4, 28-31. 
[11] Wei, X.J. (2019) The Reflection and Outlook on the Study of Teachers' IT-Based Teaching Ability. Open Journal of Social Sciences, 4, 206-212.

https://doi.org/10.4236/jss.2019.74017 